\title{
The Implications of High-Z First-wall Materials on Noble Gas Wall Recycling
}

\author{
K. Schmid, T. Schwarz-Selinger, W. Jacob, R. Dux and The ASDEX Upgrade Team \\ Max-Planck-Institut für Plasmaphysik, Boltzmannstrasse 2 D-85748 Garching, Germany \\ e-mail contact of main author: Klaus.Schmid@ipp.mpg.de
}

\begin{abstract}
Recent experiments in ASDEX Upgrade have experienced surprisingly high He plasma impurity concentrations. Such high He concentrations have not been observed with $\mathrm{C}$ walls, they were only observed since the increase of the W first-wall coverage of ASDEX Upgrade to 85\%. The high He plasma concentration appears to be linked to the fraction of $\mathrm{W}$ surfaces open to plasma contact that are not covered by boronization layers and to the number of He glow discharges performed for wall conditioning prior to normal plasma operation. This pointed to the different retention and release properties of $\mathrm{W}$ and $\mathrm{C}$ for He. To elucidate these differences dedicated laboratory experiments have been performed. To study the retention, different types of W and $\mathrm{C}$ targets, including those used in ASDEX Upgrade, were implanted with ${ }^{3} \mathrm{He}$ at $200 \mathrm{eV}$ and $600 \mathrm{eV}$ and the amount of retained He was determined through thermal effusion spectroscopy (TES) and ion beam analysis (IBA) methods. These experiments showed that $\mathrm{W}$ can retain up to 10 times more He than $\mathrm{C}$ depending on the energy of the implanted ${ }^{3} \mathrm{He}$. The differences in the release of $\mathrm{He}$ from $\mathrm{W}$ and $\mathrm{C}$ surfaces due to particle bombardment was investigated by exposing the ${ }^{3} \mathrm{He}$ implanted $\mathrm{W}$ and $\mathrm{C}$ surfaces to a ${ }^{4} \mathrm{He}$ or $\mathrm{H}_{2}$ plasmas and measuring the loss of ${ }^{3} \mathrm{He}$. It was found that for $100 \mathrm{eV}$ bias three times more He is released from $\mathrm{W}$ than from $\mathrm{C}$ exposed to an $\mathrm{H}_{2}$ plasma. For $100 \mathrm{eV}{ }^{4} \mathrm{He}$ between 2 and 10 times more ${ }^{3} \mathrm{He}$ was released from $\mathrm{W}$ than from $\mathrm{C}$ depending on the type $\mathrm{W}$ and $\mathrm{C}$ compared. The stronger release of He from $\mathrm{W}$ due to particle bombardment can be explained by the higher retention in combination with the comparable release rates of He from $\mathrm{W}$ and $\mathrm{C}$.
\end{abstract}

\section{Introduction}

With the transition from low-Z first-wall materials such as graphite (C) to high-Z materials such as tungsten (W) the operating parameters of fusion experiments have to be adjusted to be compatible with the new material properties. The most prominent issues like minimizing $\mathrm{W}$ erosion and $\mathrm{W}$ plasma impurity accumulation are well investigated [1] and appear to be manageable. But apart from erosion $\mathrm{W}$ and $\mathrm{C}$ also have very different retention and recycling properties for hydrogen $(\mathrm{H})$ or helium $(\mathrm{He})$ and other noble gases. While a lot of experiments have been conducted on $\mathrm{H}$ retention and transport in $\mathrm{W}[2,3]$ the experimental database for $\mathrm{He}, \mathrm{Ne}$ or Ar retention in $\mathrm{W}$ and wall recycling is less detailed. The reason is that retention of noble gases has not been considered an important issue compared to the problem of $\mathrm{H}$ (tritium) accumulation in first-wall materials and the resulting radiation inventory. However, recent experiments in ASDEX Upgrade have observed surprisingly high He plasma impurity concentrations in specific low density discharges. Such high $\mathrm{He}$ concentrations have previously not been observed with $\mathrm{C}$ walls. The He concentration has gradually increased during the past campaigns during which the $\mathrm{W}$ first-wall coverage of ASDEX Upgrade was stepwise increased to now 85\%. This effect is illustrated in FIG. 1 a) and b) which show the photon flux on the He II Lyman, $\alpha$ line at $30.4 \mathrm{~nm}$, which is measured on a line of-sight observing the inner heat shield during the limiter phase of the ramp up the for graphite (a) and W coated (b) inner heat shield tiles. The photon flux is a measure of the He influx from the inner heat shield. With the graphite tiles the maximum He influx is roughly one order of magnitude lower than for the $\mathrm{W}$ coated tiles. The trend of an increased He influx into the plasma with a $\mathrm{W}$ wall compared to a $\mathrm{C}$ wall is also visible in the corresponding electron density data depicted in the second line of plots below the photon flux data in FIG. 1. 


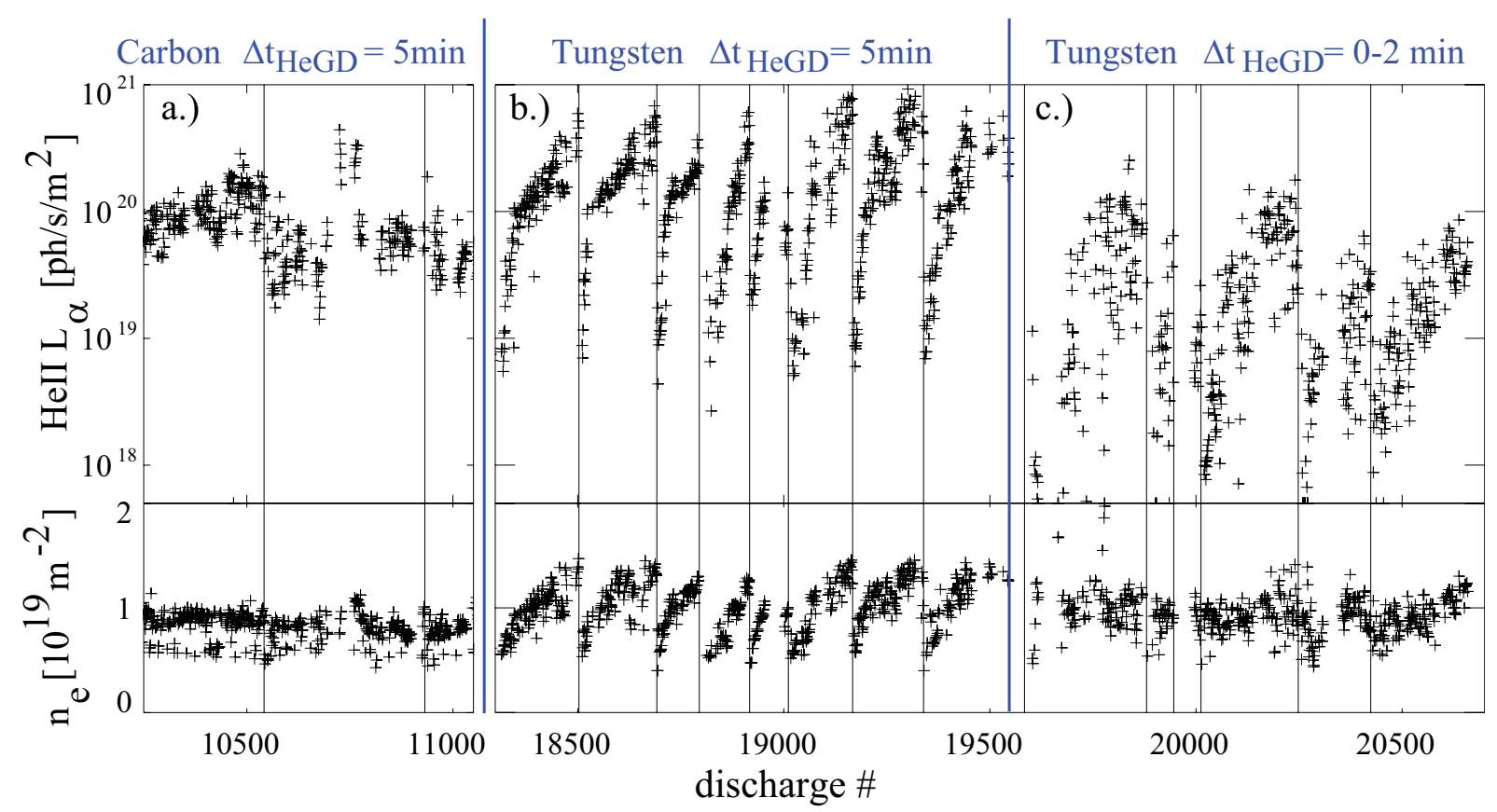

FIG. 1 First line of graphs: HeII Layman a photon flux ( He influx) at the inner heat shield in AUG during the limiter phase of the ramp-up for Graphite and W first-wall tiles and different He glow discharge durations. Second line of graphs: corresponding electron density data

The observation of the high He influx is apparently linked to the boronization and wall conditioning by He glow discharges. Boronization [4] is performed on average every four weeks and the wall is conditioned by He glow discharge cleaning between discharges. After each boronization the He influx is sufficiently small, but as the B layers are eroded during the discharges the He influx is strongly increasing. The gradual increase of the He influx after boronization is visible in FIG. 1 b) which shows the He influx from the inner heat shield with W coated tiles. After each boronization indicated by the vertical lines the He influx recovers within a few shots. Reducing the number and duration of He glow discharges allowed to mitigate the problem as can be seen in FIG. 1 c). It shows He influx after the number and duration of the He glow discharges time had been reduced. By shortening the He glow discharge time from 5 to 2 minutes the He influx was reduced almost back to the values found for the graphite tiles. There are indications that a similar issue also exists with $\mathrm{Ne}$ that emanates from Ne puffs used to mitigate disruptions in ASDEX Upgrade. After such a mitigated disruption very high levels of $\mathrm{Ne}$ are found in the plasma. Again as for He the amount of $\mathrm{Ne}$ in the plasma depends on the number of discharges since the last boronization.

These experimental observations led to the following proposed explanation for the influence of the $\mathrm{W}$ first-wall on the He plasma impurity concentration. Initially, after the boronization, the He levels in the plasma are low and as the boronization layer is removed during the discharge the underlying $\mathrm{W}$ surface is exposed to both the experimental $\mathrm{H}$ or $\mathrm{D}$ discharges and He glow discharges performed in between. The $\mathrm{W}$ surfaces are loaded with He during the glow discharge which is subsequently driven out of the $\mathrm{W}$ first-wall during the $\mathrm{H}$ or $\mathrm{D}$ discharges and released into the plasma. The release of He during the discharge from the implanted walls occurs both through particle bombardment and thermal effusion. In order to explain the different behaviour of $\mathrm{C}$ and $\mathrm{W}$ a substantial difference in the He retention and recycling properties has to be assumed. Also the boronization layers must retain only very little He since otherwise the high He plasma concentrations would also appear directly after the boronization. 
The retention of $\mathrm{He}$ in $\mathrm{W}$ and $\mathrm{C}$ and $\mathrm{B} / \mathrm{C}$ compounds has been investigated in the literature $[5,6,7,8,9,10]$. However, most of the data were obtained in ion beam experiments at keV energies and elevated temperatures. According to this literature data both $\mathrm{W}$ and $\mathrm{C}$ saturate after an implanted He fluence of the order of $10^{18} \mathrm{~cm}^{-2}$ and can retain up to $10 \%$ of the implanted He. No experimental data at low implantation energies and temperatures or on particle-induced release of He from $\mathrm{W}$ and $\mathrm{C}$ exists to our knowledge. Therefore, to elucidate the difference in He retention and release between C and W in AUG, dedicated laboratory experiments at low energies $(\sim 100 \mathrm{eV})$ and temperatures $(\sim 300 \mathrm{~K})$ were performed.

In these experiments both the implantation and retention of He in different types of $\mathrm{W}$ and $\mathrm{C}$ targets and the release of He from these targets due to particle impact were investigated. Also the He retention in boronization layers taken from AUG was measured. The experiments were designed to mimic the He implantation during He glow discharge cleaning in AUG and the subsequent particle-induced release during the discharge ramp up. In addition the thermal effusion of He from $\mathrm{C}$ and $\mathrm{W}$ was investigated through thermal effusion spectroscopy to determine the onset temperature of He effusion.

This paper will discuss the differences in He retention in different types of graphite and W targets and the particle-induced release from these targets at low implantation energies and temperatures.

\section{Experiments}

The implantation and particle-induced release experiments were performed in a low temperature electron cyclotron resonance (ECR) plasma chamber. The ECR plasma is ignited inside a metal cage and the ions are extracted from that cage by applying a DC bias to the sample stage which is situated $120 \mathrm{~mm}$ below the cage. This setup encloses the microwave energy inside the metal cage which assures that the samples are not heated by the microwave and maintain a temperature of $\sim 350 \mathrm{~K}$ as measured by a thermocouple inside the sample stage. For the experimental data presented here the sample stage holding the targets was biased negatively with respect to ground at $200 \mathrm{~V}$ or $600 \mathrm{~V}$ during the ${ }^{3} \mathrm{He}$ implantation and at $100 \mathrm{~V}$ during the particle-induced release experiments. These energies were chosen to mimic the average $\mathrm{He}$ and $\mathrm{H}$ particle energies at the AUG inner heat shield during He glow discharge cleaning and during the limiter phase of a $\mathrm{H}$ plasma discharge.

To measure the difference between $\mathrm{C}$ and $\mathrm{W}$ with respect to He retention and recycling different types of graphite and $\mathrm{W}$ targets were exposed to the ECR plasma: Fine grain graphite (FG), W coated fine grain graphite (PVD-W) as used in AUG, solid polycrystalline W (W-Solid), Pyrolythic Graphite cut parallel (Pyro-Par) and perpendicular (Pyro-Perp) to the graphene planes, and boronization layers on PVD-W (Boronization). The FG samples were manufactured by Ringsdorf ${ }^{(\mathrm{R})}$ and the W-PVD samples were coated with $\mathrm{W}$ by Plansee ${ }^{(\mathrm{R})}$ using physical vapour deposition, both are identical to the tiles used in AUG. The Boronization samples were taken from the inner heat shield in AUG after the last boronization of the 2004 campaign. These samples were implanted with ${ }^{3} \mathrm{He}$ in the fluence range from $10^{16}$ to $10^{18} \mathrm{~cm}^{-2}$. ${ }^{3} \mathrm{He}$ was used because in can be detected with high sensitivity using nuclear reaction analysis (NRA). To drive out the implanted ${ }^{3} \mathrm{He}$ during the particle-induced release experiments the targets where exposed to $\mathrm{H}_{2}$ or ${ }^{4} \mathrm{He}$ plasmas. $\mathrm{H}$ and ${ }^{4} \mathrm{He}$ were used to asses the difference in ${ }^{3} \mathrm{He}$ release due to the different erosion rates of the implantation zone with pure physical sputtering $\left({ }^{4} \mathrm{He} \rightarrow \mathrm{C} \& \mathrm{~W}, \mathrm{H} \rightarrow \mathrm{W}\right)$ and physical + chemical sputtering $(\mathrm{H} \rightarrow \mathrm{C})$. The ECR plasma was operated at $0.5 \mathrm{~Pa}$ during the $\mathrm{He}$ - and at $1 \mathrm{~Pa}$ during the $\mathrm{H}_{2}$-plasma 
operation. The gas flow rate for He was $10 \mathrm{sccm}$ and $27 \mathrm{sccm}$ for $\mathrm{H}$. The forwarded microwave power was roughly $150 \mathrm{~W}+/-10 \%$ for both the $\mathrm{He}$ and $\mathrm{H}_{2}$ plasmas.

The data presented here stem from two experimental campaigns differing in the measurement of the implanted ion fluence (particles $/ \mathrm{cm}^{2}$ ). During the first campaign the flux was measured by exposing hard a-CH layers with a known erosion rate $\left(\mathrm{nm} / \mathrm{Particle} / \mathrm{cm}^{2}\right)$ and measuring the thickness change (nm) during the plasma exposure. In the second campaign a differentially pumped retarding field analyser (RFA) was used to measure the flux (particles $/ \mathrm{cm}^{2} \mathrm{~s}$ ) and then through time integration the implanted fluence. Both methods are inaccurate by at least a factor of two. Therefore to allow for direct comparison between different target types, the targets were exposed simultaneously to assure that they all were exposed to the same fluence. For the particle-induced release experiments two samples of each type were first implanted with ${ }^{3} \mathrm{He}$ then one set of samples was removed and the rest was exposed to ${ }^{4} \mathrm{He}$ or $\mathrm{H}$. Still for the particle-induced release experiments the large error in the $\mathrm{H}$ or ${ }^{4} \mathrm{He}$ fluence makes it difficult to compare different exposures. Therefore, only the ${ }^{3} \mathrm{He}$ release of different targets from the same set of exposures (same ${ }^{3} \mathrm{He}$ and ${ }^{4} \mathrm{He}$ or $\mathrm{H}$ fluence) is directly compared.

After the plasma exposures the retained amount of ${ }^{3} \mathrm{He}$ was measured using (NRA) by utilizing the $\mathrm{D}\left({ }^{3} \mathrm{He}, \mathrm{p}\right){ }^{4} \mathrm{He}$ reaction. A $414 \mathrm{keV} \mathrm{D}$ ion beam was used for NRA measurement and an analysis dose of $20 \mu \mathrm{C}$ was accumulated for each spectrum to assure good counting statistics. The measured proton peak integrals were converted to ${ }^{3} \mathrm{He}$ areal densities using the measured cross-section data from [11]. The thermal release of He from the samples were measured through thermal effusion spectroscopy (TES). The TES setup uses a Pfeifer ${ }^{(\mathrm{R})}$ DMM-422 quadrupole mass spectrometer (QMS) and has a base pressure of $10^{-9}$ mbar. For the TES measurement the samples were heated in a glass tube oven at a rate of $15 \mathrm{~K} / \mathrm{s}$. The sample temperature is determined from the oven temperature using a calibration that was performed using a thermocouple attached to an identical reference sample inside the glass tube.

\section{Results and discussion}

\subsection{He-retention}

In FIG. 2 the retained amount of ${ }^{3} \mathrm{He}$ as function of the implantation fluence is shown for the different $\mathrm{W}$ and $\mathrm{C}$ target types at $200 \mathrm{eV}$ and $600 \mathrm{eV}$ implantation energy. The retention data for both $\mathrm{C}$ and $\mathrm{W}$ targets shows little or no fluence dependence indicating that within the fluence range available in this experiments the implantation zone was saturated with He. This is not unexpected since at the low implantation energies the penetration depth $R_{P}$ of He into $\mathrm{W}$ and $\mathrm{C}$ is in the order of $\sim 3.4 \mathrm{~nm}+/-1 \mathrm{~nm}$ and $2.6 \mathrm{~nm}+/-1 \mathrm{~nm}$ respectively. Thus the implantation zone is quickly saturated. From the retained fluence and $R_{P}$ and the number density (W: $6.3210^{22} \mathrm{~cm}^{-3}$, C: $1.110^{23} \mathrm{~cm}^{-3}$ ) an average He concentration of the order of $\sim 10 \%$ in $\mathrm{W}$ and $\sim 2 \%$ in $\mathrm{C}$ in the implantation zone can be estimated. 


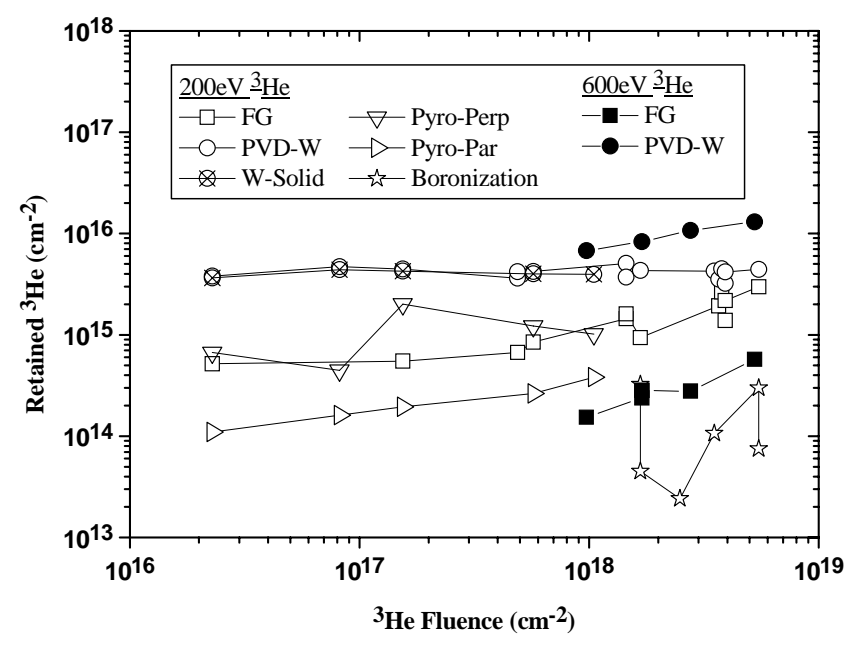

FIG. 2 He retention in different types of graphite and tungsten targets at $200 \mathrm{eV}$ and $600 \mathrm{eV}$.

From all the investigate target types the $\mathrm{W}$ materials retained the largest amount of He as can be seen in FIG. 2. For the $200 \mathrm{eV}$ implantations the AUG type fine grain graphite retains roughly an order of magnitude less He than W. At $600 \mathrm{eV}$ implantation energy it almost retains 2 orders of magnitude less He than W. The fact that the FG targets retain less He at $600 \mathrm{eV}$ as compared to $200 \mathrm{eV}$ whereas the $\mathrm{W}$ targets retain more is due to the different sputter yields of $\mathrm{C}$ and $\mathrm{W}$ by the implanted He. The erosion rate of $\mathrm{C}$ by $600 \mathrm{eV}^{3} \mathrm{He}$ is 6 times higher than that of $\mathrm{W}$ and thus the He implantation zone in $\mathrm{C}$ is continuously eroded and the implanted He is lost already during implantation.

The retention data for the boronization layers show a huge scatter which is mainly due to the inhomogeneity of the boronization layer on the AUG tile from which the samples were cut. Still it can be concluded from FIG. 2 that the boronization layers retained the least amount of He.

To test the thermal release of He from some of the FG and PVD-W targets were degassed in the TES setup. The resulting TES spectra are shown in FIG. 3. The TES spectra do not return to the same QMS signal but saturate at some elevated background level. The reason for this is the bad He pumping efficiency of Cryo pumps or Turbo molecular drag pumps. Therefore we only draw qualitative conclusions from the TES spectra. By comparing the graphite data (solid symbols) and the $\mathrm{W}$ data (open symbols) the same trend as in the NRA measurements becomes visible: $\mathrm{W}$ retains significantly more He than $\mathrm{C}$. The onset of out gassing of He from both $\mathrm{C}$ and $\mathrm{W}$ starts at around $400 \mathrm{~K}$ and should therefore not occur during the implantation which was performed at temperatures $<350 \mathrm{~K}$. 


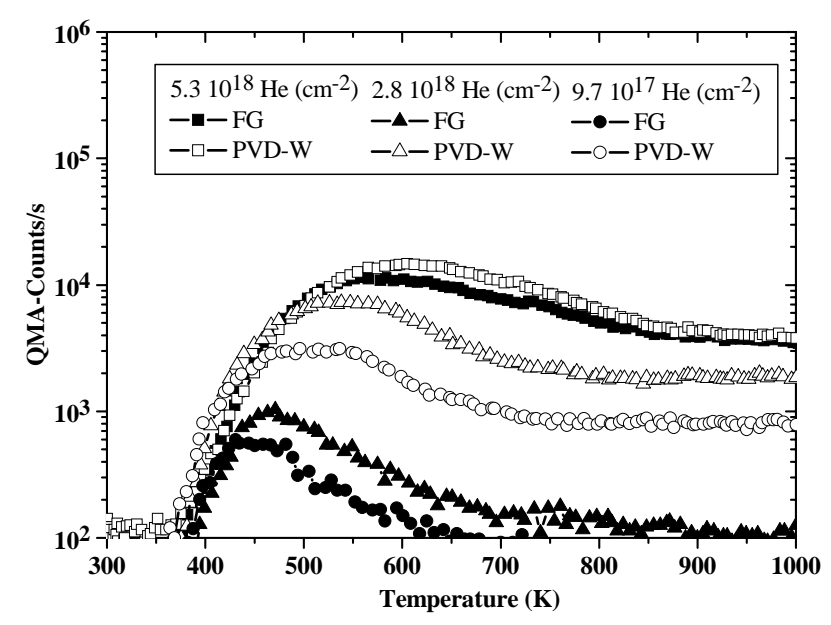

FIG. 3 TES spectra of FG and PVD-W targets implanted with ${ }^{3} \mathrm{He}$ at $600 \mathrm{eV}$.

\subsection{Particle-induced He release}

The ratio of the on average released ${ }^{3} \mathrm{He}$ fluence from $\mathrm{W}$ to that from $\mathrm{C}$ due to ${ }^{4} \mathrm{He}$ and $\mathrm{H}$ bombardment is shown in FIG. 4a and 4c, respectively, for two different initial ${ }^{3} \mathrm{He}$ implantation fluences. The average thereby runs over the released fluence by the different $\mathrm{C}$ and $\mathrm{W}$ target types each exposed to the same ${ }^{3} \mathrm{He}$ and ${ }^{4} \mathrm{He}$ or $\mathrm{H}$ fluences. The fluences of ${ }^{4} \mathrm{He}$ and $\mathrm{H}$ used to drive out the ${ }^{3} \mathrm{He}$ in FIG. 4a and 4c are indicated in the plot.
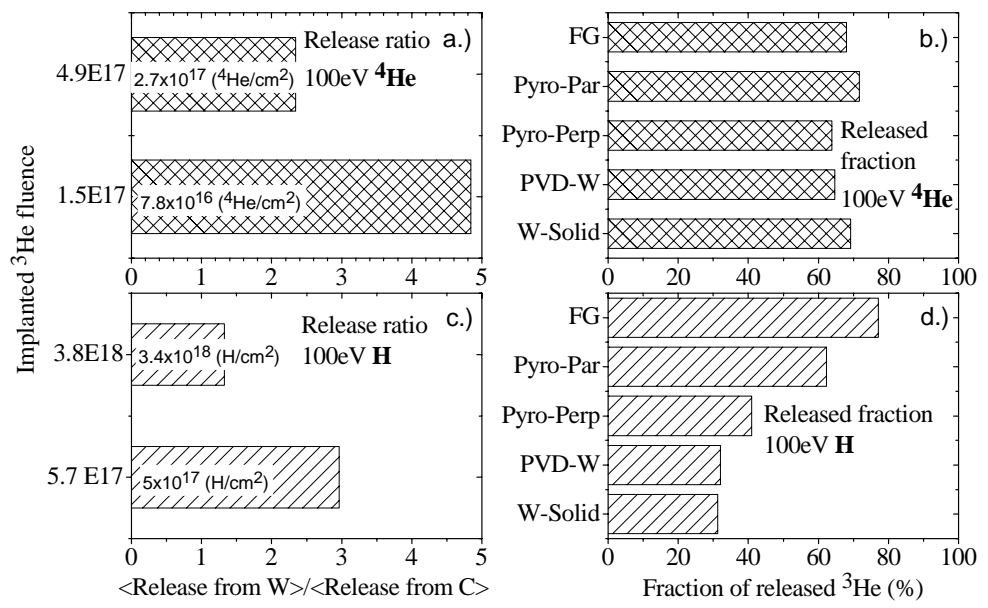

FIG. 4 The ratio of released ${ }^{3} \mathrm{He}$ due to ${ }^{4} \mathrm{He}($ a) or $\mathrm{H}(\mathrm{c})$ bombardment. The fraction in $\%$ of the implanted ${ }^{3} \mathrm{He}$ released due to ${ }^{4} \mathrm{He}(\mathrm{b})$ or $\mathrm{H}(\mathrm{d})$ bombardment for the different $\mathrm{W}$ and $\mathrm{C}$ targets

In both release experiments the average amount of ${ }^{3} \mathrm{He}$ released from the $\mathrm{W}$ targets is larger than that from the $\mathrm{C}$ targets by a factor of 2 to 5 . For a comparison of the released fluence from AUG type PVD-W to that from FG tiles yields an even higher ratio than the average, close to a factor of 10 . The amount released depends on both the ${ }^{3} \mathrm{He}$ retained during implantation and the release probability $\xi$ defined as the number of ${ }^{3} \mathrm{He}$ released per incident ${ }^{4} \mathrm{He}$ or $\mathrm{H}$. $\xi$ depends on the amount ${ }^{3} \mathrm{He}$ still retained within the range of the impinging ${ }^{4} \mathrm{He}$ or $\mathrm{H}$ particles and thus decays exponentially with the applied fluence of ${ }^{4} \mathrm{He}$ or H. Therefore, $\xi$ can not be determined from the current measurements, further experiments with better flux measurement would be necessary to measure the amount of ${ }^{3} \mathrm{He}$ released as function of the 
${ }^{4} \mathrm{He}$ or $\mathrm{H}$ particle fluence. However, one can still compare the fraction of the retained ${ }^{3} \mathrm{He}$ released through the ${ }^{4} \mathrm{He}$ or $\mathrm{H}$ bombardment for $\mathrm{C}$ and $\mathrm{W}$ targets that have been exposed to the same ${ }^{3} \mathrm{He}$ and ${ }^{4} \mathrm{He}$ or $\mathrm{H}$ fluences, respectively. In FIG. 4 the released fraction in \% of retained ${ }^{3} \mathrm{He}$ due to ${ }^{4} \mathrm{He}$ b) and $\mathrm{H} \mathrm{d}$ ) bombardment is shown. The initially implanted ${ }^{3} \mathrm{He}$ fluence was $1.510^{17} \mathrm{~cm}^{-2}$ for the ${ }^{4} \mathrm{He}$ and $5.710^{17} \mathrm{~cm}^{-2}$ for the $\mathrm{H}$ experiment. The fluence used to drive out the ${ }^{3} \mathrm{He}$ was $810^{16} \mathrm{~cm}^{-2}$ for the ${ }^{4} \mathrm{He}$ and $510^{17} \mathrm{~cm}^{-2}$ for the H experiment. FIG. 4 b) shows that for ${ }^{4} \mathrm{He}$ driven particle-induced release $\mathrm{C}$ and $\mathrm{W}$ targets loose roughly the same fraction of the retained ${ }^{3} \mathrm{He}$ whereas for $\mathrm{H}$ driven release in FIG. 4 d) $\mathrm{C}$ targets loose roughly twice as much ${ }^{3} \mathrm{He}$ as the $\mathrm{W}$ targets in our experiments.

The particle-induced release of ${ }^{3} \mathrm{He}$ from $\mathrm{C}$ and $\mathrm{W}$ materials due to ${ }^{4} \mathrm{He}$ or $\mathrm{H}$ bombardment occurs through three different processes: Direct sputtering of ${ }^{3} \mathrm{He}$ from the first few monolayers of the target surface due to kinematic processes in collision cascade, effusion of He from regions of the implantation zone that are uncovered as a result of the target erosion during the implantation and enhanced diffusion of He in the saturated regions of implantation resulting in diffusion of He out of the target. In a purely kinematic picture, based on TRIDYN [12] calculations one would expect $\mathrm{W}$ to release ${ }^{3} \mathrm{He}$ with a $\xi$ roughly three times that of $\mathrm{C}$ for $100 \mathrm{eV}^{4} \mathrm{He}$ or $\mathrm{H}$. This is due to efficient sputtering of ${ }^{3} \mathrm{He}$ by particles reflected inside the surface, knocking ${ }^{3} \mathrm{He}$ out of surface in a forward collision on their way out of the surface. In our experiments, C releases ${ }^{3} \mathrm{He}$ with a $\xi$ equal (for ${ }^{4} \mathrm{He}$ ) or larger (for $\mathrm{H}$ ) than that of $\mathrm{W}$ therefore these kinematic processes appear to be overshadowed by the other ${ }^{3} \mathrm{He}$ loss mechanisms.

An explanation for the stronger release of ${ }^{3} \mathrm{He}$ from $\mathrm{C}$ compared to $\mathrm{W}$ during $\mathrm{H}$ bombardment is that in our experiment the targets are exposed to $\mathrm{H}^{+}$ion and $\mathrm{H}^{0}$ atom fluxes. While at a bias of $100 \mathrm{eV}$ (corresponding to $33 \mathrm{eV}$ per $\mathrm{H}$ for the dominant $\mathrm{H}_{3}{ }^{+}$plasma species) $\mathrm{W}$ is not eroded, the combination of $\mathrm{H}^{+}$ions and $\mathrm{H}^{0}$ atoms leads to a strong chemical erosion of the ${ }^{3} \mathrm{He}$ implantation zone in $\mathrm{C}$ [13] thus releasing large amounts of the implanted ${ }^{3} \mathrm{He}$ from the uncovered regions of the implantation zone.

During the ${ }^{4} \mathrm{He}$ driven release experiments the ${ }^{4} \mathrm{He}$ was implanted into a ${ }^{3} \mathrm{He}$ saturated implantation zone. Therefore in equilibrium for each implanted ${ }^{4} \mathrm{He}$ another He has to diffuse out of the sample. This He isotope exchange in a saturated implantation layer was already described in [14]. Thus the release rate $\xi$ in the beginning of this isotope exchange process is equal to 1 for both $\mathrm{W}$ and $\mathrm{C}$ targets. As the amount of retained ${ }^{3} \mathrm{He}$ declines, $\xi$ decreases exponentially with the ${ }^{4} \mathrm{He}$ fluence with an e-folding length only weakly dependant on the material through the different ${ }^{4} \mathrm{He}$ reflection coefficients. In equilibrium all ${ }^{3} \mathrm{He}$ has been removed from within the ${ }^{4} \mathrm{He}$ range. Therefore the final released ${ }^{3} \mathrm{He}$ fraction depends on the ratio $\chi$ of the ${ }^{4} \mathrm{He}$ range to the width of the ${ }^{3} \mathrm{He}$ implantation zone. For $100 \mathrm{eV}^{4} \mathrm{He} \chi$ is similar for both $\mathrm{W}(\sim 0.7)$ and $\mathrm{C}(\sim 0.6)$. Thus $\mathrm{W}$ and $\mathrm{C}$ release roughly the same fraction of the initially implanted ${ }^{3} \mathrm{He}$.

Based on these experimental results the issue of increased He influx from the AUG inner heat shield with W coated tiles compared to $\mathrm{C}$ tiles can be understood: After a boronization, glow discharge cleaning results in He implantation into boronization layers which retain the least amount of He compared to $\mathrm{C}$ or $\mathrm{W}$. Thus discharges directly after a boronization feature only little He influx into the plasma. As the boronization layer is eroded the underlying $\mathrm{W}$ is exposed to the He glow discharges, which retains roughly 10 times more He than the previously installed $C$ tiles. During the limiter phase of the startup the He release from the AUG heat shield will probably be a combination of particle-induced release and thermal 
release since the plasma wetted areas can reach temperatures well above the $400 \mathrm{~K}$ required for He release in the TES experiments in FIG. 3. This should result in similar release probabilities $\xi$ for both $\mathrm{W}$ and $\mathrm{C}$. Thus one can expect an increase of the He influx of up to a factor of 10 for a $\mathrm{W}$ wall compared to a $\mathrm{C}$ wall which would match the experimental data from AUG in FIG. 1.

\section{Conclusions}

Experimental data from AUG shows a factor 10 increase in the He influx during the limiter phase of the discharge since the transition from a $\mathrm{C}$ to $\mathrm{W}$ first-wall. The magnitude of the He influx is closely linked to number of discharges since the last boronization and the number of He glow discharges in between plasma operation. This suggests a process that becomes significant as the boronization layers are eroded and the $\mathrm{W}$ surfaces become exposed to the He glow discharges.

The comparison of different $\mathrm{W}$ and $\mathrm{C}$ materials implanted with $\mathrm{He}$ in dedicated lab experiments showed that $\mathrm{W}$ surfaces retain the largest amount of He compared with $\mathrm{C}$ surfaces or boronization layers. TES analysis of the $\mathrm{W}$ and $\mathrm{C}$ samples showed that He starts to degas from the samples at approximately $400 \mathrm{~K}$. The particle-induced release of He from $\mathrm{W}$ and $\mathrm{C}$ through $\mathrm{H}$ bombardment is similar within a factor two depending on how quickly the He implantation zone in $\mathrm{C}$ is eroded. Based on the high He retention in W compared with $\mathrm{C}$ or the boronization layers, the source of the increased He influx in AUG and the correlation to the boronizations and the He glow discharges can be explained.

In ITER or a future reactor the wall temperature will be above $400 \mathrm{~K}$ and therefore the He accumulation should not occur at the same levels as they were found in AUG. Also the larger plasma volume to first wall surface area ratio of a reactor would mitigate the problem: Even if same amount was retained per $\mathrm{cm}^{-2}$ and completely released into the plasma, the resulting plasma concentrations would scale with the inverse of the major radius and thus be much smaller. It can therefore be concluded that the higher He retention of W compared to C should not hinder the use of $\mathrm{W}$ in ITER or in a future reactor.

[1] R. Neu, R. Dux, A. Kallenbach, T. Pütterich et.Al., Nucl. Fusion 45 (2005) p. 209

[2] O.V. Ogorodnikova, J. Roth, M. Mayer, J. of Nucl. Mat. 313-316 (2003) p. 469

[3] V.Kh. Alimov. K. Ertl, J. Roth, K. Schmid, J. of Nucl. Mat. 282 (2000) p. 125

[4] V.Rohde, R.Dux, et al., "Wall conditioning in ASDEX Upgrade", accepted for publication in J. Nucl. Mat.

[5] N. Hashimoto, J. D. Hunn, et al., Fusion Science and Techn., 47, (2005) p. 881

[6] Zhang Fu, N. Yoshida, et al., J. Nucl. Mat., 329-333 (2004), p. 692

[7] K. Tokunaga, R. P. Doerner, et al., J. Nucl. Mat., 313-316, (2003), p. 92

[8] T. Hino, Y. Yamauchi, et al., J. Nucl. Mat., 266-269, (1999), p. 538

[9] H. Yanagihara, Y. Yamauchi, T. Hino, et al., J. Nucl. Mat., 241-243, (1997), p. 1098

[10] R. A. Langley, R. S. Belewer, J. Roth, J. Nucl. Mat., 76-77, (1978), p. 313

[11] H. S. Bosch, G. M. Hale, Nucl. Fusion, 32, (1992), p. 611

[12] W. Möller, W. Eckstein et al., Computer Physics Communications, 51 No. 8, (1988), p. 355

[13] A. A. Hassz, O. Auciello, P. C. Stangeby et al. J. Nucl. Mat., 128-129 (1984) p. 593

[14] J. Roth et al., Nucl. Inst. Meth., 149 (1978), p. 53 